\title{
Planning and Performance: The Effect of Form Focused Guided Planning on Learner Performance
}

Suman Laudari

\begin{abstract}
Task-based language teaching (TBLT) has been a dominant approach in the field of ELT for some time now. However, it has complexities regarding its use in a foreign language context. It is said that focusing only on interaction may not be enough in guiding learners to use language correctly, so learners need exposure to grammar rules, and teachers presume that TBLT does not allow it. But, learners' attention could be directed to the grammar forms during task planning to facilitate noticing of linguistic code. To this end, this small-scale study collects discourse data from an adult EFL learner to evaluate whether guiding learners' attention to grammar during pre-task planning is of any help. The study concludes that guiding learners' attention facilitates in producing more accurate and complex discourse than leaving learners on their own during the task planning.
\end{abstract}

Key words: TBLT, planning, form focused planning, guided planning, $C A F$

\section{Introduction}

Tasks have been promoted as one of the major tools to promote interaction (Long, 1996) and 'pushed output' (Swain, 1998) in second language classrooms. However, in many foreign language (FL) contexts, task-based teaching is uncommon due to difficulties associated with contexts (Mochizuki \& Ortega, 2008). One of the problems is the beginning level of learner proficiency which makes it difficult to hold interaction in the FL. Secondly, it is also thought that a purely interaction based classroom does not help in acquiring grammar rules, which forms the core part of English language teaching in FL contexts such as Nepal. This is mostly because it is thought that the emphasis on interaction might override the attention to linguistic codes (Skehan \& Foster, 2001), and grammar teaching might be neglected.

Therefore, it has been argued that some kinds of orientation of linguistic code (grammar) can be given to learners during the interaction (Long \& Robinson, 1998). This is because, such orientation helps learners notice forms during meaningful contexts and develop learner interlanguage systems. Pedagogically, this forms an approach of teaching both grammar and communication in the English as a Foreign Language (EFL) context (Ortega, 2007) and affects language learning positively. To this end, this small-scale study is carried out to

$92 \quad$ Journal of NELTA, Vol 18 No. 1-2, December 2013 
examine if orienting learners' attention to grammar forms during the pre-task planning results in any variation to learners' subsequent performance.

This paper is divided into three sections. The first section reviews planning, its types and performance in relation to planning. Next, in the same section, I also briefly review Trade Off and Cognition Hypothesis in relation to planning, which is followed by a short critique on studies that have explored the effect of form-focused planning. Afterwards, the rationale of the present study is presented. In the second section, I introduce my participant, research methodology and procedure. Subsequently, in the third section, I discuss the findings of this study followed by limitation and summary.

\section{Planning and its types}

Planning is a deliberate thinking on our task, usually before or during the task. Planning, an inbuilt and inherent aspect of all kinds of task performance, is, in essence, a problem solving activity (Ellis, 2005). With regard to language production, planning is taking decision about the content, the language, lexical items, and other linguistic devices to be used while performing a task. Planning has drawn quite much of research interest (Ellis, 2009) because it is thought that it (planning) aids noticing and attention, a prerequisite for both input and output (Robinson, 2001). Given that input and output are prerequisite for language acquisition, planning, in consequence, is thought to lead to better language production, and may also aid language acquisition. Further, it may also correlate with input/output processing, working memory, and focus-on-form (Ellis, 2005).

Planning might occur at different stages of language production. Based on when planning takes place during performance, planning is categorized into "pre-task planning" and "withintask planning". Pre-task planning, as the name suggests, occurs before the task. It can becategorized into rehearsal and strategic planning (Ellis, 2005). On the other hand, 'Within-task planning' is the planning that takes place during the actual performance of a task. Within-task planning is generally referred as on-line planning. Ellis categorizes within-task planning into two forms based on "the extent to which task performance is pressured or unpressured" (p.4).

\section{Planning and performance}

Having reviewed planning in the earlier section, I will briefly review performance with regard to planning and also discuss how performance is measured. However, given the word limit I will review only the studies that have manipulated strategic planning.

There exists "a plethora of studies on planning and its effect on performance" (Ortega, 2005, p. 77). Specifically, these studies have examined how three types of planning- strategic, rehearsal and within task planning- affect performance. The effect of planning in task-based research is measured with reference to three dimensions of language production. These aspects are called complexity, accuracy and fluency 
(CAF). They entail that if a learner is proficient in an L2, she/he should be able to use the language fluently and accurately using complex language (Ellis, 2009). In other words CAF represents the linguistic quality of learner discourse.

Complexity is defined as the use of more advanced and diverse target language features. Skehan and Foster (1999) define it as "...the capacity to use more advanced language with the possibility that such language may not be controlled so effectively" (p.96). Complexity is taking risk about the use of new and complex features so they are prone to errors. On the other hand, accuracy, in general, refers to error free production or the degree of deviancy from the established norm of language (Housen \& Kuiken, 2009). Skehan and Foster (1999), define accuracy as "[t]he ability to avoid error in performance, possibly reflecting higher levels of control in the language as well as conservative orientation, that is, avoidance of challenging structures that might provoke error" (p.97). Likewise, they define fluency as " $[t]$ he capacity to use language in real time, to emphasize meanings, possibly drawing on more lexicalized systems" (p.96). Also, fluency is being able to use more advanced language and having greater control over language.

The results of the previous studies on CAF framework are quite mixed. Many studies have indicated that planning affects fluency positively (Mehnert, 2003; Kawauchi, 2005). However, those studies have produced mixed results on the effect of planning on complexity. While some studies have concluded that planning has a positive effect on complexity (Sangarun, 2005; Skehan \& Foster, 2005) other studies have reported that planning has no effect on complexity (Yuan \& Ellis, 2003;Mochizuki \& Ortega, 2008). Also, the results of the previous studies on accuracy are also quite mixed. Some of these studies have found planning aiding accuracy (Kawauchi, 2005; Mochizuki \& Ortega, 2008) but others have noted planning not resulting in higher accuracy (Yuan \& Ellis, 2003).

\section{Noticing, attention, trade off and cognitive hypothesis}

From this brief review, it can be said that the strategic planning aids task performance but there are factors/ variables that mediate with planning and affect performance. Additionally, given that learners have limited attentional capacity, planning provides them with opportunities to opt for the language features that they are not comfortable using (Skehan, 2009). Further, planning allows learners to access the linguistic resources in their mental repertoire, and produce the discourse as per the context. However, it is worth noting that no prior studies on CAF dimension have found planning affecting all three dimensions. In this regard, Skehan (2009) further argues that it is very unusual to see planning leading to increased performance in all three dimensions of CAF.

Additionally, Skehan (2009) argues that there exists a competitive relation between CAF dimensions, especially 
accuracy and complexity. That is to say, when learners allot attentional resources to one of these three areas of $\mathrm{CAF}$, it happens at the detriment of other two, resulting in a trade-off. However, Robinson (2001) and Robinson and Gilabert (2007) deny the existence of trade off and claim that both the accuracy and complexity can be raised by manipulating the dimensions of task complexity. Robinson (2001), in his Cognitive Hypothesis, argues that planning makes the task easy as they have time to work on the form. This frees up their attentional resources and can access the automatic and readily available linguistic features in their mental repertoire (Ellis, 2003). This, in effect, results into higher accuracy, complexity and also raised fluency.

In the same vein, it is also argued that providing learners with complex and challenging task makes them more focused on task (Michel, 2013). This pushes learners towards more complex linguistic realization. This moves their attention away from fluency to form. To put in other words, designing a complex task pushes both accuracy and complexity (Michel, 2013). Furthermore, planning is argued to contribute to both input (Schmidt, 1990; 1994) and output processing (Swain, 1995; 2005) as it aids the bottom-up processing required to attend to form. Consequently, planning is said to contribute to interlanguage development.

Having reviewed CAF triads in relation to performance and Trade-Off Hypothesis in this section, I will now review studies that have explored the effect of form focused planning on subsequent performance in the next section.

\section{Empirical Studies on form focused guided planning}

There are a few studies that have guided learners to focus on meaning or form or both during the task planning (Sangarun, 2005). Studies by Ellis (1987; focus on form), Williams (1992; focus on meaning), and Foster and Skehan (1999, focus on form and meaning both) oriented students to focus on either meaning or form, whereas the studies by Crookes (1989), Foster and Skehan (1996), and Wendel (1997) infused both form and meaning orientation during pre-task planning. However, these studies were inconclusive and limited (for a detailed review see, Sangarun, 2005). Reviewing all the studies mentioned above is beyond the remit of this paper, hence, only two recent studies, Sangarun (2005), and Mochizuki and Ortega (2008), will be reviewed here for they serve the purpose of the present paper.

Sangarun (2005), motivated to find the effect of specific foci (meaning-focus, form-focus, and meaning/form-focus) on oral performance, is a between participants design with 40 Thai EFL participants of intermediate level of English. The participants were asked to perform two different tasks, an instruction task and an argumentative task, under one of the four different planning conditions: minimal planning, form focused, meaning focused and form, during the pre-task planning. 
This study concluded that planning, overall, affected oral performance positively. However, the author failed to find any significant difference among the focus groups. Moreover, she concludes that all learners had a tendency to focus on meaning irrespective of the type of orientation they were provided.

Mochizuki and Ortega (2008), unlike Sangarun, aimed to explore the effect of pre-task planning that embedded grammatical guidance on performance. Their study was also a between participants design with 56 Japanese high school students. The learners worked in pair on a pictorial task. The participants were 'blindly divided' into no-planning, unguided planning and guided planning groups. This study concluded that unguided planners outperformed the no-planners and guided planners in terms of fluency. But, when it came to accuracy guided planners outperformed the other two groups. Nonetheless, there was no significant difference between the three groups in terms of complexity.

Both of these studies indicate that guiding learners' attention aids performance. But, specifically, Sangarun (2005) failed to find any difference between the three planning conditions. So it is inconclusive whether it is beneficial to guide learners, especially adult learners', attention to form during the pre-task planning stage. Unlike Sangarun (2005), Mochizuki and Ortega (2008) concluded that guiding learners' attention to a specific form aids accuracy. However, the guided learners were outperformed in terms of fluency and complexity. So, these studies do not answer firmly if guiding learners' attention to specific form is beneficial to interlanguage development.

\section{Rationale for the present study}

From the theoretical discussion above, it is evident that strategic planning has more consistent effects on fluency than on complexity or accuracy (Skehan, 2009). However, studies that guided learner focus have found that such orientation is effective in promoting accuracy, complexity and fluency (Sangarun, 2005). It hints that guiding learners' attention may be beneficial. In addition, allowing learners to plan strategically is also thought to contribute to language development (Ellis, 2005; Sangarun, 2005).

However, as most of these studies have combined all different foci in a single study and followed 'between participants' design, comparing learner discourse to draw effective conclusion is challenging. This is because individual differences and task types affect the performance (Ellis, 2003,). So, the discourse produced may be affected by these variables to conclude that such planning helps in acquiring form. Moreover, as the number of studies that have guided learner attention to specific form is small, there is a dire need that such studies be conducted so the results might help English as a foreign language teachers to decide whether form focused induction benefits language learning. To this end, this study is motivated to explore the effect of pre-task planning with some grammar induction on 
performance when a task is repeated. For the same, I have set the following as my research objective:

- How does planning with form focused induction affect learner performance when the task is repeated?

\section{Present study}

\section{Research tool and procedure}

\section{Design}

This is a "within subject" small scale study with two planning conditions, no planning and pre-task (guided strategic planning) conducted on a single participant. I chose to use a within subject design because by using a within subject design I expect to compare the data to reveal the differences between the output of performance performed under two different planning conditions with some form focused induction during the second occasion. This might be useful in drawing firmer conclusions.

\section{Participant}

The number of participant in this study is one. She is an adult learner of English from Taiwan. She is 23 and studying at a UK university. She was studying in the UK for 6 months at the time of data collection. As part of the enrollment at her university, she also took an IELTS test in which she scored 6.5. Besides, she also attended the English for Academic Purpose Course (EAP) at her university for four weeks before her course formally started. She is named $\mathrm{W}$ for the purpose of this study.

\section{Task}

The task chosen to be used in this research study was a narrative task. This is because the participant had traveled to another city of the UK to celebrate the Chinese New Year day with her friends. Next, this task would fulfill all the criteria that an ideal task ought to fulfill (Ellis, 2003). The task is a meaning focused task given that she was asked to recount her journey to the other city and how she celebrated the festival with her friends. Next, there was a real need for communication as the interlocutor comes from a different context and did not know anything about Chinese New Year celebration. Thirdly, $W$ had to rely on her own resources to complete the activity as the task was monologic in nature. Lastly, the outcome was to convey the message across.

\section{Procedure}

The participant was chosen based on the fact that she had agreed to volunteer to provide data upon the researcher's request. She was requested to give the convenient date and time for the data collection. As per her request, the first data was collected on February 28, 2013. The task was repeated on March 17,2013 . While, the task took 9 minutes 24 seconds to complete on the first occasion, it lasted for 9.20 minutes on the second occasion. There was no planning on the first occasion. Nonetheless, when the task was repeated, 5 minutes was given as planning time following Mochizuki and Ortega (2005). W could make notes during planning however; she was not 
allowed to use the note during the task performance.

It is also important to note that $\mathrm{W}$ was explicitly told that the past tense is used while recounting a personal experience on the second occasion. But, it should be noted that no any other instruction was given regarding planning. This, as has been presumed, would increase the validity of the research as this research is closer towards the planning dimension and form-focused induction.

Both the tasks were recorded for the subsequent transcription. Then, the transcripts, and the recording were compared and analyzed to measure the CAF dimensions.

\section{Data analysis}

\section{Measure}

CAF measures used in this study were adopted from Yuan and Ellis (2003) and partly from Wendel (1997). The following section briefly describes these measures:

\section{Fluency measures}

To measure fluency, number of syllables per minute and meaningful syllables were counted as in Wendel (1997), and Yuan and Ellis (2003). These scholars contend this measure takes both the amount of speech and the length of pauses into account. The following is a description of these measures:

1. Number of syllables per minute: For this, total number of syllables was counted first. It was then divided by the number of seconds used to complete the task and was multiplied by 60 .

2. Number of meaningful syllables per minute was counted. It was done like in A but, as in Yuan and Ellis (2003), with all syllables, words, phrases that were repeated, reformulated, or replaced excluded.

\section{Complexity measures}

To measure complexity two measures were adopted from Yuan and Ellis (2003). These measures are:

1. Syntactic variety: with regard to syntactic variety, the ratio of clauses to $\mathrm{T}$ unit, a main clause plus any other subordinate clauses attached to or embedded within it, was calculated. As the nature of the task was monologic, T-unit was chosen as the measure instead of others.

2. Syntactic variety: As for the syntactic variety, the total number of different verb forms used by $\mathrm{W}$ was tabulated and counted. Basically, it reflected both the variety and also the complexity in her discourse.

\section{Accuracy measures}

The two measures used to calculate accuracy are described below:

1. Error-free clauses: For this, the total number of error free clauses in the participant's narrative was counted and then it was divided by the total number of clauses. All errors related to morphology and lexical choices were considered. Further to this, all 
syntactic errors that impeded the comprehension of meaning were also considered. Equally, the correctly reformulated clauses were counted as correct, as long as they did not contain any of the errors mentioned above. However, such reformulations, following Kawauchi (2005), are just counted as a single clause.

2. Correct verb forms: The percentage of accurately used verbs in terms of tense, subject-verb agreement, and modality were tabulated and calculated.

Please see appendices 2, 3, and 4 for a detailed understanding of how these measures were calculated.

\section{Results}

Table 1 presents the summary of the statistics for all measures used to gauge CAF triads in this study. However, it should be noted that the findings refer to a single participant so may not represent what other learners would do. As can be seen in the table, the performances under unplanned and planned conditions were compared. The table indicates

\begin{tabular}{|c|c|c|c|c|}
\hline Criteria & \multicolumn{2}{|c|}{ Task - 1 (- plan) } & \multicolumn{2}{|c|}{ Task -2 (+ plan) } \\
\hline Total words & \multicolumn{2}{|l|}{991} & \multicolumn{2}{|l|}{939} \\
\hline Time spent & \multicolumn{2}{|c|}{8.50 minutes (510 seconds) } & \multicolumn{2}{|c|}{8.30 minutes (498 seconds) } \\
\hline Type token ratio & \multicolumn{2}{|l|}{284} & \multicolumn{2}{|l|}{262} \\
\hline Complexity & \multicolumn{2}{|l|}{1.81} & \multicolumn{2}{|l|}{2.06} \\
\hline Ratio of clauses to $\mathrm{T}$ units & & & & \\
\hline Verb forms & Correct use & Incorrect use & Correct use & Incorrect use \\
\hline Simple past & 35 & 3 & 67 & 2 \\
\hline Other past forms & & 1 (p. con) & 1 (p. cont) & \\
\hline Simple present & 40 & 37 & 13 & 13 \\
\hline Other present & 1 (pr. Cont) & $\bullet$ & & \\
\hline Modal verbs & 3 & $\bullet$ & 1 & 1 \\
\hline Passive & - & - & 2 & 2 \\
\hline Infinitive & 9 & 0 & 16 & 1 \\
\hline Gerund & 5 & 2 & 1 & 0 \\
\hline Future & 0 & 1 & 0 & 0 \\
\hline \multicolumn{5}{|l|}{ Accuracy } \\
\hline \multicolumn{2}{|l|}{ Total No. of Clause } & 138 & \multicolumn{2}{|r|}{120} \\
\hline \multicolumn{2}{|l|}{ Error free Clauses } & 47 & \multirow{2}{*}{\multicolumn{2}{|c|}{58}} \\
\hline \multicolumn{2}{|l|}{ (\% of error free clauses) } & $34.05 \%$ & $48.33 \%$ & \\
\hline \multicolumn{2}{|c|}{ Percentage of accurately used verbs } & $68.11 \%$ & \multicolumn{2}{|r|}{$84.17 \%$} \\
\hline \multicolumn{2}{|l|}{ Fluency } & & & \\
\hline \multicolumn{2}{|l|}{ No. of syllable per minute } & \multirow{2}{*}{$\begin{array}{l}145.2 \\
48.82\end{array}$} & \multicolumn{2}{|r|}{141.2} \\
\hline \multicolumn{2}{|c|}{ No. of meaningful syllables per minute } & & \multicolumn{2}{|r|}{47.71} \\
\hline
\end{tabular}

that the fluency measures are slightly higher on the first occasion than on the second occasion. Though, previous studies on pre-task planning have concluded that fluency is generally positively influenced by planning (e.g. Ellis, 2005, Kawauchi, 2005), the results of this study are to the contrary. Though the difference is not that high, it is seen that the participant was less fluent during the second occasion.

Conversely, the complexity measure indices show increment on the second occasion. The syntactic complexity measure index is higher on the second occasion. Likewise, the ratio of clauses to $\mathrm{T}$ units is also higher on the second occasion. Equally, the participant is able to maintain syntactic variety on the second occasion. Given it is a narrative task that requires the use of the simple past tense, the occurrence of the simple past tense is high. However, they are 
meaningfully used and $\mathrm{W}$ also used other forms of verbs whenever possible (see, Appendix-1).

Similarly, the table above shows an increased accuracy on the second performance as compared to the first occasion. Looking at the first measure of accuracy, percentages of error free clauses, it can be said that the learner has higher accuracy on the second occasion. The percentage of error free clauses have increased by more than $14 \%$ on the second occasion though the difference in total words, type-token ratio, and time taken to complete was not much different. Equally, the percentage of accurately used verbs has increased by more than $16 \%$ under the planned condition. Interestingly, $\mathrm{W}$ has used the past tense more correctly and consistently on the second occasion. In addition, the incorrect use of the present tense was lowered drastically under the planned condition. Moreover, in the transcript of her narrative (see, Appendix 1), it is seen that she has been able to use the present tense correctly on the second occasion.

\section{Discussion}

Planning, in general, seems to have impacted the subsequent production positively in this study. The performance that involved planning and some orientation towards linguistic code has resulted in higher complexity and accuracy. Following Mochizuki and Ortega (2008) and Sangarun (2005), it can be said that guided planning with orientation to form results in higher and consistent use of the intended linguistic form. This may be because, as Mochizuki and Ortega (2008) argue, some external guidance about the linguistic code during pretask stage may prepare learners to attend the form correctly.

Regarding fluency, this study does not support the results of previous studies which have concluded that planning, in general, leads to higher fluency. This might be because of the awareness provided during the strategic planning stage. The orientation seems to have guided learners' attention to the correct, consistent and meaningful use of the past tense (Sangarun, 2005). As accuracy requires learners to 'draw on their rule-based system' (Ellis, 2005), learners are likely to be conscious of the use of readily available language chunks and other features that aid fluency. This is also because when accuracy is focused learners are likely to deploy strategies to avoid errors. These in consequence, affect the fluency (Ellis, 2005).

Furthermore, given that L2 adult learners learn better while provided with some kind of focus-on-form (Ellis, 2005), awareness towards the specific form might have contributed to the better performance (higher complexity and accuracy) of this learner. This is because, working memory is limited which limits learners' capacity to attend to form and meaning simultaneously (Schmidt, 1990; 1994). As it is natural that learners might overlook the structures that are nonsalient, while they opt for meaning, drawing their attention to forms may contribute in the consistent and accurate use of specific form in the 
subsequent production (Mochizuki \& Ortega, 2008).

Interestingly, looking at the fluency measure it can be said that there is a slight evidence of trade-off. This is because, the fluency measures, as said earlier, are lower under the planned condition than that in the unplanned condition. It seems to suggest that when learners are given explicit information about the target structure that ought to be used to perform a task, they become conscious about the correct use of the form in deterrent to fluency. In consequence, fluency might be overridden by accuracy in the discourse. This finding is in contrary to Robinson's (2001) claim that planning makes the task easy and frees up the attentional constraints resulting into increased performance in overall. This is because second language learners possess limited attentional capacity and working memory (Skehan, 1996). Additionally, the result also does not support the results of the previous studies in which fluency is accompanied by complexity or accuracy (Skehan, 2009).

Further, it is also evident that the attentional resources required to overcome the constraints related to accuracy might have negatively influenced the fluency of $W$. In addition, it also seems that the focus on meaning might have taken place at the expense of the other. In other words, as argued by Skehan (2009), a concern to use the past tense correctly might have resulted in higher accuracy, but at the expense of fluency. Additionally, looking at the lexical diversity, total number of words and type token ratio, we may infer that $W$ was more concerned about conveying the meaning on the first occasion so she used higher number of simple present tense than simple past on the first occasion. This is further supported by the observation that she has used higher number of clauses on the first occasion than on the second occasion. However, on the second occasion, as accuracy was focused, all her attention might have been deployed in overcoming the constraints related to accuracy.

Additionally, this study supports the overall findings of Mochizuki and Ortega (2008) in that accuracy is positively influenced by guided planning. This might be because learners tend to be more accurate when they are provided with external guidance about grammatical features that enable them to accomplish the activity more accurately (Mochizuki \& Ortega, 2008). However, in their studies the guided planners did not have increased performance in terms of complexity, but in the present study the complexity measures and lexical variance are greater on the second occasion. This might be because of the repetition of the task as learners might choose to use complex linguistic structures to convey the meaning effectively (Bygate, 1996).

Furthermore, looking at the result it can be said that $W$ was concerned in conveying the message on the first occasion. But, on the other hand, as she was directed to form on the second occasion, she was concerned about being accurate rather than fluent. This 
provides the evidence that Ellis (2003) makes about learners having different goals while performing a task. So, the 'awareness raising' during the pre-task planning might have influenced her strongly to vie for accuracy. Equally, following Bygate (1996), it can be said that performance of a task on the second occasion, when it is repeated, may be better. However, depending upon the nature of the planning and the focus, the CAF measures may not be equally affected. Lastly, though, Bygate (1996) claims that task repetition leads to increase in all three components of CAF, it is not supported in this research, because on the second occasion the fluency measures have decreased. Finally, though a small scale study, this research has implications for pedagogy in that it indicates that L2 adult learners could be guided toward form during strategic planning in that such planning might result into increased and consistent use of the target form and also possibly in interlanguage development.

\section{Limitations and summary}

One of the limitations of the study could be that the number of participants is small, which may make the scope of the results rather narrow; hence one should be cautious in generalizing the findings. However, what the findings indicate seems to be intriguing. This study lends support to the fact that some kinds of form focused induction during the planning stage may prepare adult learners of English to use the targeted form more consistently and correctly (Long \& Robinson, 1998). Further, it is evident that guided planning may aid the correct use of the desired forms in the task performance which might counter the problem of teaching grammar. However, it should also be noted that it may happen at the expense of fluency.

\section{About the author}

Mr. Laudari, Hornby Scholar 2012/13, is a teacher of English and has been teaching English for almost a decade now. Currently, he is working as an adjunct faculty at Kathmandu University, School of Education and Ace Institute of Management. His research interests are motivation in second language learning, planning and task performance, and TBLT.

\section{Reference}

Bygate, M. (1996). Effects of task repetition: Appraising the developing language of learners. In J. Willis and D. Willis (Eds.), Challenge and Change in Language Teaching (pp. 136-146). Oxford: Macmillan, Heinemann.

Clark, H. and G. Clark. (1977).Psychology and Language: An introduction to psycholinguistics. New York NY: Harcourt, Brace, Jovanovich.

Crookes, G. (1989). Planning and interlanguage variation. Studies in Second Language Acquisition11, 367383.

Ellis R. (1987). Interlanguage variability in narrative discourse: Style shifting in the use of the past tense. Studies in Second Language Acquisition, 9, 1-20.

Ellis, R. (2003). Task-based language learning and teaching. Oxford: Oxford University Press 
Ellis, R. (2005). Planning and task-based performance: Theory and research. In R., Ellis (Eds.), Planning and Task Performance in a Second Language (pp. 334). Amsterdam: John Benjamins.

Ellis, R. (2009). The differential effects of three types of task planning on the fluency, complexity, and accuracy in 12 oral production. Applied Linguistics, 30(4), 474-509.

Foster, P. \& P. Skehan. (1996). The influence of planning on performance in taskbased learning. Studies in Second Language Acquisition 18(3): 299-324.

Housen, A., \& Kuiken, F. (2009). Complexity, accuracy, and fluency in second language acquisition. Applied linguistics, 30(4), 461-473.

Kawauchi, C. (2005). The effects of strategic planning on the oral narratives of learners with low and high intermediate proficiency. In R. Ellis (Eds.), Planning and Task-Performance in a Second Language (pp. 143-164). Amsterdam: John Benjamins.

Long, M. H. (1996). The role of the linguistic environment in second language acquisition. In W. Ritchie and T. Bhatia (Eds.), Handbook of second language acquisition (pp. 413-468). New York: Academic Press.

Long, M. H., \& Robinson, P. (1998). Focus on form: Theory, research, and practice. In C. Doughty \& J. Williams (Eds.), Focus on form in classroom second language acquisition (pp. 15-41). New York: Cambridge University Press.

Mochizuki, N. \& Ortega, L. (2008). Balancing communication and grammar in beginning-level foreign language classrooms: A study of guided planning and relativization. Language Teaching Research, 12, 11-37.

Ortega, L. (2005). What do learners plan? Learner driven attention to form during pre-task planning. In R., Ellis (Eds.), Planning and Task Performance in a Second Language (pp. 77-110). Amsterdam: John Benjamins.

Ortega, L. (2007). Meaningful L2 practice in foreign language classrooms: A cognitive-interactionist SLA perspective. In R. DeKeyser (Eds.), Practicing in a second language: Perspectives from applied linguistics and cognitive psychology (pp. 180-207). New York: Cambridge University Press.

Robinson, P. (2001). Task complexity, task difficulty, and task production: Exploring interactions in a componential framework. Applied Linguistics 21(1), 27-57.

Robinson, P. \& Gilabert, R. (2007). Task complexity, the cognition hypothesis and second language learning and performance. International Review of Applied Linguistics in Language Teaching 45(3), 161-176.

Sangarun, J. (2005). 'The effects of focusing on meaning and form in strategic planning. In R. Ellis (Eds.), Planning and task performance in a second language (pp. 111-141). Amsterdam: John Benjamins.

Schmidt, R. 1990.The role of consciousness in second language learning. Applied Linguistics 11, 129-158.

Schmidt, R. (1994). Deconstructing consciousness in search of useful definitions for applied linguistics. AILA Review11, 11-26.

Skehan, P. (1996). A framework for the implementation of task-based instruction. Applied Linguistics, 17, 3862.

Skehan, P. (2009). Modelling second language performance: Integrating complexity, accuracy, fluency, and lexis. Applied linguistics, 30(4),510-532. 
Skehan P. \& Foster, P. (1999). The influence of task structure and processing conditions on narrative retellings. Language Learning, 49(1), 93-120.

Skehan, P., \& Foster, P. (2001). Cognition and tasks. In P. Robinson (Eds.), Cognition and second language instruction (pp. 183205). New York: Cambridge University Press.

Skehan, P. \& Foster, P. (2005). Strategic and on-line planning: The influence of surprise information and task time on second language performance. In R. Ellis (Eds.): Planning and taskperformance in a second language (pp. 193-218). Amsterdam: John Benjamins.

Swain, M. (1995). Three functions of output in second language learning. In G. Cook and B. Seidhofer (Eds), For H. G. Widdowson: Principles and practice in the study of language (125-144). Oxford: OUP.

Swain, M. (1998). Focus on form through conscious reflection. In C., Doughty and J. Williams (Eds.), Focus on form in classroom second language acquisition (pp. 64-81). New York: Cambridge University Press.
Swain, M. (2005). The output hypothesis: Theory and research. In E., Hinkel (Eds.), Handbook of research in second language teaching and learning (pp. 471-484). Lawrence, NJ: Lawrence Erlbaum Associates.

Wendel, J. (1997). Planning and second language narrative production. Unpublished doctoral dissertation, Temple University, Japan.

Williams, J. (1992). Planning, discourse marking, and the comprehensibility of international teaching assistants. TESOL Quarterly26, 693-711.

Yuan, F. \& Ellis, R. (2003). 'The effects of pre-task and on-line planning on fluency, complexity and accuracy in L2 monologic oral production. Applied Linguistics 24(1), 1-27.

\section{Appendices}

Please follow the Link for the appendices

https://drive.google.com/file/d/ OBzifyEnIgxrJRXIOaDhYc3NKSTA/ edit?usp=sharing 